https://doi.org/10.15407/fd2020.02.102

UDC 141.112

Dmytro SEPETYI, PhD in Philosophical Sciences,

Associate Professor at the Department of Social Disciplines,

Zaporizhzhia State Medical University,

26, Mayakovskyi Ave., Zaporizhzhia, 2669035

dmitry.sepety@gmail.com

https://orcid.org/0000-0003-2110-3044

\title{
JOHN FOSTER'S PHENOMENALISTIC IDEALISM UNDER SCRUTINY
}

The article discusses John Foster's last attempt at refutation of physical realism and defence of phenomenalistic idealism. Main Foster's arguments against physical realism, the argument from «the problem of perception» and the argument from the inscrutability of intrinsic content of the external reality are scrutinized and found wanting. The argument from «the problem of perception» is shown to fail against «the decompositional view» because it falsely assumes that the perception of an object, if it is mediated by some processes and states, requires the perception of those mediating processes and states. The argument from the inscrutability of intrinsic content is found unsuccessful because physical realism can accommodate Kantian agnosticism about intrinsic contents, while holding that physical reality is knowable in all structural and dynamical respects that in fact constitute the realm of study of natural sciences. Foster's further argument that involves the spatial swap scenario is shown to beg the question: a physical realist can plausibly and arguably deny either the logical possibility of such a scenario, or Foster's idealism-favouring construal of it. On the other hand, it is pointed out that Foster's treatment of the timing of the prehuman history of the Universe is gravely unsatisfactory and suggests the refutation of phenomenalistic idealism.

Keywords: physical realism, phenomenalistic idealism, perception, intrinsic content, empirical immanence.

\section{Introduction}

In the recent philosophy of mind, John Foster was one of the most prominent representatives of idealism. In his book, $A$ World for Us: The Case for Phenomenalistic Idealism [Foster, 2008], John Foster made an ambitious attempt to refute physical realism and argue for the view he calls «phenomenalistic idealism». He made similar attempt earlier, in the book The Case for Idealism [Foster, 1982], but that book did not find much response - probably, because its argument was too technical and, by Foster's own later admission, «made enormous, and arguably intolerable, demands on the patience of the reader» (Foster 2008, viii). In $A$ World for Us, Foster

Citation: Sepetyi, D. (2020). John Foster's phenomenalistic idealism under scrutiny. Філософська думка, 2, 102-118. https://doi.org/10.15407/fd2020.02.102. 
presented an improved version of the theory and argument in a much less technical and more accessible way. A similar argument against physical realism for Berkleyan idealism was advanced by Howard Robinson. Robinson described his argument as a simplified version of that presented by Foster in 1982 [Robinson, 1985: p. 184]. Thus, the argument in [Foster, 2008] is much clearer and more comprehensible than its earlier version in [Foster, 1982], and much more detailed than that advanced by Robinson. This gives us reason to consider it as the most exhaustive defence of this variety of idealism, and makes it worth attention. However, as far as I was able to find out, it did not raise discussion beyond several short book reviews. Given that such fundamental defences of idealism are far from abundant in the contemporary philosophy of mind, I think that the issue of the tenability of Foster's arguments deserves close examination. In this paper, I discuss and criticize main Foster's arguments against physical realism, analyze the relationship between it and phenomenalistic idealism, and argue against the latter.

\section{Phenomenalistic idealism versus physical realism}

The commonly held view about physical reality is that it exists and has its properties independently of human and animal minds, except insofar as minds influence behaviour of humans and animals. This view is called «physical realism». What Foster takes to be wrong with it?

Most generally, Foster's complaint against physical realism is that it «does not leave the physical world with the right kind of empirical immanence to count as our world in the requisite sense - a sense which allows it to be the world which our ordinary physical beliefs are about» [Foster, 2008: p. 164]. Unlike it, phenomenalistic idealism enables us to «represent the physical world as having the empirical immanence it needs if it is to form a world for us» [ibid.: p. vii]. ${ }^{1}$

The main principles of phenomenalistic idealism are as follows:

(1) it «takes the physical world to be something whose existence is ultimately constituted by facts about human sensory experience, or by some richer complex of non-physical facts in which such experiential facts centrally feature» [ibid.: p. 101];

(2) it assigns «the central world-creative role» to «the system of control over the course of human sensory experience that disposes it to systematically conform to its world-suggestive pattern, and, in the context of certain endowments of the human mind... this conformity creates the systematic appearance of a certain kind of world at the human empirical viewpoint» [ibid.: p. 164-165]. Foster calls this system of control «the sensory organization»; I think that the clearer name, to convey the meaning, would be «the world-suggestor». The world-suggestor «constitutively creates the physical world» by controlling our experiences in a way that makes «things to appear systematically worldwise» [ibid.: p. 113].

\footnotetext{
${ }^{1}$ Cf.: Howard Robinson: «...a transcendental world beyond the veil of perception would not be the physical world that we inhabit» [Robinson, 1985: p. 181].
} 
One may wonder how the world-suggestor (which is not, as physical realism says and we are used to think, the physical world itself) can «constitutively create» the physical world rather than just suggest to us that there is such a world whereas in fact there is no. A series of well-known world-suggestors come to mind, such as Descartes' deceitful demon, «The Matrix» movie, and Putnam's «brain in a vat». What is there about Foster's world-suggestor that makes the world it suggests a genuine physical world rather than illusion? Foster's answer turns out to be that it is the fact that the world-suggestor is God or is created by God, and God has the appropriate authority. For me, such authoritarian answer seems hugely suspect. Can it be that if a world is suggested by God, it is a genuine world - not in virtue of there being this world but in virtue of it being suggested by God? And can it be that if exactly the same world is suggested by someone else and not on God's commission, it is not a genuine world but a sham - not because really there is no this world but because the suggestor is not God, and is not authorized by God?

It seems that to accept such an implausible view, we should have very strong reasons to reject physical realism. Do Foster's arguments provide such reasons? Let us see.

Foster advances two major arguments.

\section{The argument from «the problem of perception»}

The first is concerned with «the problem of perception», which can be formulated in three theses:

(1) there are two rival general views about the proper way of our understanding our perceptual access to the physical world, which Foster calls «decompositional view» and «fundamentalist view»;

(2) they exhaust the range of possibilities (that is, there is no more alternatives);

(3) neither of them can be made to yield a satisfactory account so long as we retain «the common-sense assumption that the physical world is ontologically independent of the human mind - that it is something whose existence is logically independent of facts about human mentality» [ibid.: p. 1].

In other words, Foster's first argument aims to demonstrate that physical realism makes a satisfactory account of our perceptual access to the physical world impossible. Given that we certainly have such an access, this (if true) proves that physical realism is false.

Now what are the two rival general views and what is wrong with each of them taken in the context of physical realism?

The decompositional view is that whenever a person perceives a physical item, «the fact of his perceiving that item breaks down into (is constituted by the combination of) two components»:

(1) the person being in «some psychological state which is not in itself physically perceptive»,

and 
(2) certain additional facts that do not involve anything further about the person's psychological condition at the relevant time - facts that concern «the qualitative relationship of the psychological state to the physical item..., and the role of the item in causing the subject to be in that state at that time» [ibid.: p. 8].

The fundamentalist view is that whenever someone perceives a physical item, «the fact of his perceiving it is something psychologically fundamental» in the sense that it does not breaks down into (is not constituted by the combination of) those components ((1) and (2)) involved in the decompositional account; moreover, «[i]t does not, at the psychological level, break down into further facts at all»: «[i]n other words, the psychological state that is fundamentally involved in the perceiving of the relevant physical item is one that is in itself perceptive of that item» [ibid.].

In other words, the fundamentalist view is that perception involves a fundamental psychological state that is (1) wholly a matter of what is occurring in the perceiver's mind at that time and (2) is inherently physically perceptive in the sense that it «suffices for physical-item perception» - the very fact of there being that psychological state secures perceptual contact with the physical object that is perceived [ibid.: p. 9]. In contrast, the decompositional view is that the relevant psychological state is not enough; it cannot secure perceptual contact with the perceived object on its own; for there to be a perception, the relevant psychological state should go together with some non-psychological facts that establish proper causal relationship from the perceived physical object to the relevant psychological state.

Foster argues first that the fundamentalist view in the context of physical realism is untenable [ibid.: p. 14-27]. I won't dwell on Foster's argumentation to this purpose, because it is pretty bulky and involves rather technical points, so I cannot convey its gist briefly enough. Instead, I will put aside the fundamentalist view and move to the decompositional view, which seems to me more tenable and defensible.

In Foster's argument against the decompositional view, we can distinguish three stages.

The first stage. Foster focuses on the specific variety of the decompositional view - the sense data perception theory, according to which perception decomposes into (1) a causal chain from the physical object to its specific mental representations called «sense data» and (2) direct perception of the sense data. On this, Foster remarks that «it is commonly acknowledged that if what is fundamentally before the subject's mind is something which only exists in his mind, and if it only seems to him that he is perceiving something external (environmental) because his experience interprets this item in an externalist way, then the subject's impression of perceiving something external is simply mistaken, and his awareness does not reach to anything beyond the mental item itself» [ibid.: p. 31-32].

The second stage. Foster claims that this problem is «only a special instance of a general problem that affects all versions» of the decompositional view. The general problem for a decompositionalist is formulated as follows:

«What we have here, surely, is not an awareness of an external item, but only an experience which, by its causal origins, provides its subject with a representation 
of, or with information about, an external item. ... there is simply nothing in the fundamental situation envisaged by the theory that would suffice to create ... perceptual access to the external world» [ibid.].

However, this formulation of the problem is far from clear, and the claim about there being nothing to create perceptual access is debatable. One can wonder why Foster finds it that «the admission of a representation in the process of perception constituted a veil incompatible with genuine perception» [Garrett, 2010: p. 399]. And a decompositionalist can object that on his view, there is something that suffices to create perceptual access to the external world: for there to be a genuine perception of a physical object, it suffices that there are (1) the physical object, (2) an experience (such as visual or tactual) that suggests to the experiencer that there is the physical object perceived, and (3) an appropriate causal chain from the object to the experience. Foster provides neither an explanation of what constitutes the problem nor an argument that (1), (2), and (3) cannot be sufficient for genuine perception.

The third stage. Foster considers the possible objection that perhaps he is «working with too narrow a view of what is required for perceptual awareness», and that «[i]n our ordinary thinking we seem to recognize various types of case in which the perceiving of one physical item is in some way mediated by the perceiving of another». An example to consider is «that someone can watch a football match on television, when we know that his visual access to the match is channelled through his access to the patterns on the screen» [Foster, 2008: p. 32]. Against this, Foster argues that none of such examples «affords the decompositionalist the analogical support that he needs» [ibid.: p. 35].

For me, the whole of this discussion is obscure, and it is obscure because of the obscurity of the previous, second stage, of Foster's argument. If the problem with decompositionalism is not clear, then the point of appealing to such examples as watching a football match on TV, and of rebutting such appeals, will not be clear either. However, I think that the discussion of these examples, combined with Foster's remarks about the sense data theory, can provide a clue to the second stage. It can suggest a plausible conjecture about Foster's reason to think that all versions of decompositionalism founder against the same problem as the sense data theory. And it provides material for constructing an argument to that point.

Consider first cases of obviously mediated perceptual awareness, such as seeing a football match on TV. The situation here seems very similar to that with the sense-data theory: we do not perceive the football match directly; the physical object we perceive directly (if any) is the TV screen with its changing patterns of colours. If so, then (like in the case of the sense-data theory) we do not genuinely perceive the football match.

However, putting this all together does not sum up to a general argument against the decompositional view. There is only (1) an objection against the sensedata perception theory, which objection is not so much an argument but an appeal to a view that Foster takes to be commonly acknowledged and (2) an argument that 
in cases like seeing a football match on TV, the situation is analogical, and so there is no genuine perception of the objects like football matches. To be more precise, if we agree with (1), we should agree with (2) for essentially the same reason.

But how all this is supposed to undermine a version of the decompositional view distinct from the sense-data theory? It seems that our ordinary perceptions are not like watching football on TV. And a decompositionalist at issue does not hold the view that when I seem to perceive a tree out there what I really perceive is a treelike sense data in my mind.

To this, Foster could answer that in fact, our ordinary perceptions are relevantly like watching football on TV. Why so? Because no perception is direct in a strong, absolute sense. Take ordinary visual perceptions, for example. I see a tree ten meters afar in front of me. Do I directly, with no mediation, visually perceive a tree? One can deny this by appealing to the fact that there is such a mediator as the light wave between the tree and my eyes, so what I directly perceive is not a tree but the eyes-adjacent front of the wave. ${ }^{2}$ Why should we hold that some physical media, such as lightwaves, provide us with genuine visual perception of trees etc., whereas other physical media, such as TVs, fail to do so? What is the principal relevant difference? There does not seem to be any. So, if seeing a football match on TV is not a genuine perception of the football match, then my seeing a tree ten meters afar in front of me is not a genuine perception of the tree as well. And the same goes for all purported perceptions. Not only such cases as watching TV, but all cases of perception are cases «in which the perceiving of one physical item is in some way mediated by the perceiving of another».

All these considerations constitute the following argument:

(1) If the sense data theory is true, then genuine perception of physical things and events (anything outside our minds) is impossible.

(2) Seeing things or events (such as football matches) on TV is relevantly like what the sense data theory entails about our perception of physical things and events; hence, it is not a genuine perception of physical things and events (football matches etc.)

(3) Ordinary perceptions of (what we are used to take for) physical things and events are relevantly like seeing things or events (such as football matches) on TV.

Hence, ordinary perceptions of (what we are used to take for) physical things and events are not genuine perceptions of physical things and events.

Can a decompositionalist rebut this argument? I think she can, and a proper way to do it is to deny (2). Let us admit that the situation with my seeing a tree out there is not principally different from a situation of my seeing a football match on TV. However, despite Foster's suggestion, we would do well to hold that in both situations there is genuine perception, of the tree and the football match respectively. However, what is then the principal difference with the case of the sense data theory?

\footnotetext{
${ }^{2}$ Or perhaps when I seem to perceive a tree ten meters afar in front of me (and there really is a tree ten meters afar in front of me, and the illumination is normal, and my eyes are open), what I am in fact (directly) perceiving are some neuron discharges in my brain!
} 
Despite Foster's prima facie plausible description, watching a football match on TV is not a case «in which the perceiving of one physical item is in some way mediated by the perceiving of another». When a person watches the football match, she does not perceive the TV screen, and neither do she perceives the sense-data. ${ }^{3}$ The perception is not a passive result of an object's infringement upon the perceivers' senses and mind; rather it is an activity that necessarily involves an intentional stance and an intentional object, what the person expects and is tuned to see, a way she directs her attention. When a person sees a football match on the TV, she visually perceives the football match exactly because she is intentionally tuned to see a football match, not a TV screen. She uses the TV screen to see (perceive) something beyond it. To visually perceive the TV screen she needs to change her mode of attention, so as to observe the TV screen and its colour patterns rather than watch the football match. By the same token, when perceiving a football match or a tree, a person normally does not perceive their «mental representations», visual experiences (perhaps she may introspect them if she chooses to, if she pays them attention, but usually she does not). ${ }^{4}$

Thus, I think that Foster's first argument fails.

\section{The argument from the inscrutability of intrinsic content of the external reality}

However, it seems that Foster puts the major burden of invalidating physical realism on another argument, which we can call the argument from the inscrutability of intrinsic content of the external reality (of what the physical realist takes to be physical reality).

To begin with, Foster distinguishes three kinds of properties that the (purported) physical objects should have: spatio-temporal properties (size, form, relative location, and their temporal derivatives such as velocity, acceleration etc.),

\footnotetext{
${ }^{3}$ What is wrong with the sense data theory, as described above, is not that it says that perception involves mental representation but that it says that perception of physical things involves perception of mental representations. When I perceive a tree, my visual experience of perceiving a tree can be called «mental representation» of a tree; however, while having that visual experience (mental representation), I do not perceive it. At best, I can be implicitly aware of having this experience, and can become explicitly aware of it if I pay special attention to the experience. But usually, when a person perceives such things as trees, she does not pay attention to experiences; she pays attention only to the things perceived.

${ }^{4}$ Generally, I think that Foster's treatment of perception is fundamentally mistaken in that he takes it to be eventually a matter of what he calls « $\varphi$-terminal perception» [Foster, 2008: p. 7-11]. He assumes that our perception of objects (such as apples, for example) is mediated by perception of « $\varphi$-terminal objects» that have no temporal and spatial depth, such as a certain portion of the object's surface at a point of time. That assumption is false to the phenomenology of perception. When perceiving such things as apples we do perceive apples, as temporally continuous things with spatial depth, and we do not perceive any such thing as portions of apples' surface at temporal points, except in cases when we pay special attention to momentary portions of surfaces rather than apples.
} 
functional properties, that is «properties of a causal, dispositional, or nomological kind» (dispositions to influence spatiotemporal properties of physical objects or to evoke certain experiences in a certain regular, law-abiding way), and intrinsic characters of physical objects that ground spatiotemporal and functional properties (such fundamental intrinsic nondispositional qualities are often called «quiddities») [ibid.: p. 45-46]. The intrinsic character is necessary for there to be something that stands in spatial relations to one another and has dispositions to lawabidingly influence the temporal dynamics of these relations. That which stands in those relations and is so disposed (physical bodies, or fields, or waves, for example) should have an intrinsic qualitative character that makes it what it is rather than nothing (points or areas in qualityless geometrical space). The intrinsic character cannot itself be of the relational nature of spatiotemporal and dispositional (functional) properties, for it is necessary to ground any spatial relations and dispositions. However, there is a problem about these intrinsic characters - they are absolutely unknowable and inscrutable (in the sense of Kant's «things in themselves»). All we know about them is that they are somethings that ground the existence and physical dispositions of the purported physical objects. However, we cannot know what these somethings are intrinsically, in themselves. (In Foster's term, we may know them only opaquely, not transparently. ${ }^{5}$

The physical realist can bite this bullet, and admit that all our knowledge of physical reality is inevitably limited to spatiotemporal and dispositional (functional) properties. Since this knowledge is of properties of physical objects, physical realism seems to remain largely unscathed, even if it needs to assimilate some elements of Kantian agnosticism. ${ }^{6}$ What we can know, anyway, is pretty much to be

\footnotetext{
${ }^{5}$ The problem of the unknowability and inconceivability of the fundamental intrinsic nature of matter was similarly emphasized by Howard Robinson [Robinson, 1982: p. 108-123; 1985: p. 178-185].

${ }^{6}$ This «quidditist» approach is explained in more details and defended in [Langton, 1998; 2004; Lewis, 2009].
}

An alternative possibility is to deny that there are such things as fundamental non-dispositional intrinsic properties, and hold that all there is to physical things are locations and dispositions. That option is taken by quite a lot of contemporary philosophers (for some examples see [Harré, Madden, 1975; Shoemaker, 1980; Chakravartty, 2003; Whittle, 2008; Bird, 2016]). However, for many people (myself included), when they think of it well, it is incomprehensible how that network of locations and dispositions - that is, network of relations - is possible without any qualitative filling that is not relational. It is the notion of a network of relations between items that have no qualities besides being disposed to certain relations. The notion involves infinite regress or circularity that seems vicious: all qualities of any item boil down to its spatial relations (and dispositions to uphold or change those relations) to other items that have no properties beyond their spatial relations (and dispositions to uphold or change those relations) to other items that have no properties beyond [...], ad infinitum. (A useful way to make the problem clear is to begin with conceiving of a world that has only two point-particles that have no other properties except location and dispositions to influence one another's movements. Now think of it: how can there be any difference between those otherwise propertyless particles being there and moving, and there being no particles at all? Nothing that moves nothing is still nothing. And obviously, situation does not principally change if you add more such parti- 
content with: it includes «[t]he shape and size of objects, the spatial arrangements of their parts, the distances between them, their spatial paths over time, the ways in which they are disposed to behave and interact, the causal processes in which they feature, the laws of nature that govern their behaviour and interaction» [Foster, 2008: p. 46-47].

However, Foster argues that it is not the end of the troubles about the intrinsic content of physical reality, because it is not only intrinsic characters of spatially located entities (such as physical bodies, fields, and waves) that is inscrutable, but the intrinsic character of the (purported) physical space as well. The result is as follows:

«If intrinsic content is inscrutable, the only knowledge we can have of the external reality is topic-neutral: it is knowledge confined to facts about the structure and organization of this reality, and about its links with the realm of human mentality; it is knowledge that does not reveal anything about the nature of the ontological domain in which this structure and organization are realized» [ibid.: p. 93]

This still does not undermine physical realism, for the inscrutability of intrinsic content of the external reality should be admitted anyway, whether we are realists or phenomenalistic idealists. On both views, there is an external reality whose intrinsic content is inscrutable (except if this reality is God's mind), and so the only knowledge we can have of the external reality is topic-neutral knowledge about its structure and organization, and its links with human mentality. And the physical realist may be willing, and have good reasons to, retain the name «physical reality» for that external reality, even if it is knowable only in these structural, organizational and mentality-relational respects.

However, it is possible that the structure and organization of the external reality are not knowable, and that our purported knowledge of it is systematically and incorrigibly at variance with how that reality is in fact. Here (in the chapter titled «The Refutation of Realism» [ibid.: p. 129-138]) Foster's main argument against physical realism comes in. ${ }^{7}$

cles - even if there is an infinite number of such particles.) Foster's arguments, obviously, are directed to those who see such a notion as absurd.

${ }^{7}$ Cf.: Howard Robinson:

«...it is both epistemically and logically (or metaphysically, as some say in such contexts) possible that the transcendental world operates on laws quite different from those which a perfect science of the empirical world would generate. ...This creates a problem for the physical realist. The physical realist's conception of the physical world has two components. The first is that the world is mind-independent; the second is that the physical world is what physical science investigates and hence its nomological structure is what physical science approximately uncovers. Both these are necessary truths for the physical realist. ...A world not accessible to certain sorts of investigation - paradigmatically those exhibited by physical science - is not the physical world» [Robinson, 1985: p. 182-183].

Robinson emphasizes that the second component (as well as the first one) is a necessary (conceptual) truth, so that the mere logical or metaphysical possibility that the external world is unknowable by means of empirical science (in particular, physics) is sufficient to prove that the external world is not the physical world and, hence, physical realism is false, - even if in 


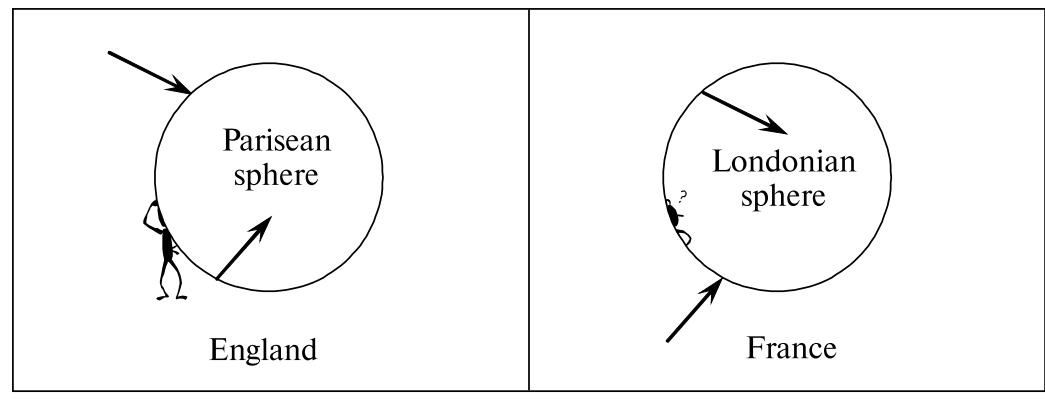

Fig. Foster's scenario of spatial swap

Foster proposes us to think of the possibility that the laws that govern the external reality (which the physical realists take to be physical reality) and its relationship with our minds are systematically perverse in such a way that we necessarily and incorrigibly take the spatial ordering of physical reality to be one way whereas in fact the spatial ordering of the external reality is another way. Suppose that the spatial ordering of objects in the external reality is such that it perfectly maps into our ideally empirically obtainable picture of physical spatial ordering, except for two spherical regions of the same size. Suppose these are regions that circumscribe London and Paris, leaving outside the largest parts of France and England. And suppose that in the external reality London is located in France and Paris in England, but the systematically perverse laws of the external reality are such that for us, empirically, everything is systematically as if London is located in England and Paris in France. No experience and no experiment can reveal to us this spatial swap, for the nomical perversion in the external reality is finely and perfectly attuned in all relevant respects to keep us in incorrigible delusion as to where London and Paris are located in external reality. (Thus, any body, or microparticle, or wavefront that reach the borderline of the Londonian sphere continues its movement, with no delay, in the Parisean sphere, and vice versa. Whenever a person traverses the borderline of the Parisean sphere, his body, including the head and the brain, are in the external reality partly in England and partly in France, but these parts act in perfect coordination, as if they are spatially adjacent, and it looks and feels for the person as if he is in England and moves in London. And so on.)

If the external reality is of such a perverse sort, which of the following two statements is true?

(I) Physically (in physical space) London is located in England, and Paris in France.

or

(R) Physically (in physical space) London is located in France, and Paris in England.

fact (not metaphysically necessarily but contingently), the external world is empirically knowable, and physics approximately uncovers its structure. 
Foster claims that the true statement is (I), because on this choice physical reality has a required «empirical immanence», which means that it fits with our empirically obtainable knowledge of physical reality. Our conception of the physical is such that in conceivable (metaphysically possible) cases of the external reality's failure to map into what is «empirically immanent» we would side the physical with what is «empirically immanent» rather than the external reality. If so, then our concept of the physical is basically the concept of empirically immanent rather than of the external reality (whether or not there is really anything like the perverse relationship we were conceiving of - even if in fact the external reality perfectly fits «empirically immanent»).

However, is it really so? I think a physical realist can make a plausible case to the contrary. Let us think better.

To begin with, a physical realist can doubt that the situation, as described, is really conceivable (in the «negative» sense of coherence), - that it does not involve some non-obvious conceptual incoherence. If our knowledge of physical reality is not about its fundamental intrinsic qualities («quiddities» or, in Foster's terms, «intrinsic content») but only about its intrinsic relations, their structure and dynamics, then it is plausible that spatial adjacency is, conceptually, a matter of the continuity of movements, and that can make the scenario of spatial swap incoherent. However, suppose, for argument sake, that either it or some other perverse scenario (one can think here of well known sceptical scenarios, such as that of brain in a vat) is coherent.

Then we have an option between two claims.

(1) By «physical reality» we mean basically the external, human-mind-independent reality, whether or not it (perfectly) maps into «empirically immanent».

(2) By «physical reality» we mean basically whatever fits the requirement of «empirical immanence» (that is, our empirically obtainable knowledge of physical reality), whether or not it fits with the external, mind-independent reality.

Why should we hold (2) rather than (1)? I rather think that (2) should be implausible, if only because it makes the definition of «physical reality» self-referring: physical reality is defined through what can be (ideally) known about physical reality.

Does the thought experiment with the spatial swap really support (2) rather than (1)? Would we really, on good thought, judge about such a situation that in it, (I) is true rather than (R)? I think that it is not straightforwardly clear, if one does not beg the question by using the requirement of «empirical immanence» as a guide for this judgment. Let us consider things yet once.

Suppose that the external reality is really that perverse way, and suppose that in some extraempirical, supernatural way we get to know it. Perhaps God Herself reveals it to us. We know of the perverse way the external reality is ordered, and are perfectly sure that this our knowledge is true, despite the fact that empirically things appear systematically otherwise. In such a case, what we would say of physical reality? Admittedly, when back to our ordinary everyday concerns, we would usually talk of London as located in England and Paris as located in France, just as a mat- 
ter of convenience for all practical purposes. However, whenever concerned not with convenience in practical matters, but with the ultimate truth of the matter, I think we would rather say that really, in fact, it is not so: really, in fact, London is located in France and Paris in England. (To remind, the situation is such that we know, and are perfectly sure, that in the external reality London is located in France and Paris in England.)

Foster explains his opinion that «given our ordinary understanding of what is involved in physical spatial arrangement» we should in the previsaged situation hold that London is in England and Paris is in France by suggesting that «our understanding of the nature of physical spatial arrangement cannot be separated from our ordinary ways of empirically assessing what forms of arrangement obtain» [Foster, 2008: p. 137]. However, this seems to be begging the question straightforwardly identifying «physical» with «empirical» rather than «external». Admittedly, in «our understanding of the nature of physical spatial arrangement» we do in fact rely on «our ordinary ways of empirically assessing what forms of arrangement obtain». But why we do so? Most plausibly, we do so because and insofar as we expect that «our ordinary ways of empirically assessing what forms of arrangement obtain» are veridical. However, the case we discuss is one in which they are not veridical.

So, it is far from clear whether we should describe the situation envisaged in the way Foster suggests or the other way around. What does it matter, however? This is a merely verbal point of no real significance at all. Nothing real hangs on it. There is, on the one side, the external reality that causes our experiences and, on the other side, the way it systematically appears to us. It is of no significance at all where we choose to put the word «physical» - on the «external» or «empirical» side, although the realist would rather choose to put it on the «external» side (because from the realist point of view, such a choice is more in keeping with aspiration of physical science, and science generally). Physical realism is not a verbal preference but a substantial view that is concerned with the existence of mindindependent external reality (whether you call it «physical» or not) and our search for knowledge about it.

However, Foster takes this verbal matter seriously as an argument that discredits physical realism and establishes that if there is the physical world, it is not a mind-independent reality but something constituted by facts about human sensory experience, and, perhaps, facts about external reality that evokes human sensory experiences. Although this external reality may have mind-independent existence and be exactly the way the physical realist conceives physical reality, Foster takes his preceding argument to establish that it does not qualify as physical reality (and, therefore, should be qualified as non-physical) because it does not satisfy the requirement of «empirical immanence». However, this begs the question, because the physical realist would deny the empirical immanence requirement as construed by Foster. Instead, he would hold that if there is mind-independent external reality that evokes our experiences, then it is this reality (its structure and internal relationships) 
that we investigate and try to attain knowledge about (both in ordinary life and in science).

Faced with the spatial swap scenario or some other radical skeptical scenario, one can wonder: how can we know that things are not that - or some other similarly perverse - way? If we cannot, then the (scientific) search for physical knowledge can be in vain, even if we do our (scientists do their) best. It seems that what scientists really achieve, or are gradually nearing to - whether external reality is benign or perverse - are the theoretical models that best fit the totality of our real and possible experiences. That may make Foster's claim look plausible. However, it can look so only if we overlook the question of what our scientific physical knowledge, or scientific physical models, are about (of). If they are about (of) the external reality, then we have come back to physical realism. If they are about something constituted by ideally obtainable empirical knowledge, then we get caught into vicious circle. There would be no material for knowledge (models) to start with. The idea of knowledge about (models of) what is constituted by possible knowledge about (models of) what is constituted by possible knowledge about (models of) [ad infinitum] is just an absurdity.

So I think that the outcome is that

indeed, our notions and scientific theories about (models of) physical reality are basically about (of) external reality,

and indeed, it is metaphysically possible that they drastically fail to correspond with that reality - that they are mostly false and not even nearing the truth.

It is metaphysically possible that what we call «scientific knowledge» fails to be «knowledge» in the traditional sense (justified true belief), in particular, that it is false. As Karl Popper (who was a staunch physical realist) explained, what we call «scientific knowledge» are just hypotheses (conjectures) that have successfully passed the trials we were capable to devise for them up to the moment. There is no guarantee that they are true, or even near the truth. We can (and it is reasonable for us to) hope that they succeed to near the truth, and point out that their nearing the truth is the best explanation of their being successful so far. But that still falls short of barring the possibility of metaphysical scenarios like that of spatial swap or wellknown radical sceptical scenarios. However, physical hypotheses (conjectures), whether or not they are true, are hypotheses (conjectures) about the external reality, its structure and internal relationship. And that is all that physical realism may need to involve epistemologically. At least, in the epistemological perspective of the hypothetico-deductive theory of knowledge and consistent fallibilism, Foster's and Robinson's arguments against physical realism miss the mark. ${ }^{8}$

\footnotetext{
${ }^{8}$ With respect to Robinson's formulation of the argument, which was quoted in the previous footnote, the reply of the physical realist and fallibilist can be as follows. Indeed, «it is both epistemically and logically (or metaphysically...) possible that the transcendental world operates on laws quite different from those which a perfect science of the empirical world would generate». And indeed, physical realism assumes that «the physical world is what physical science investigates». However, from this, it does not follow that «its nomological structure is what phys-
} 


\section{Phenomenalistic idealism and its refutation}

Now let us consider Foster's proposed alternative to physical realism, «phenomenalistic idealism». Given Foster's explanation, it really splits into two: Berkleyan idealism and something very like... physical realism.

Foster describes «phenomenalistic idealism» as the view according to which physical world is constituted by some complex of non-physical facts in which facts about human sensory experience centrally feature. What else takes part in the constitution, besides facts about human sensory experience? It is something he calls «the sensory organization», or «the control system», and what we may call «the world-suggestor». Foster allows for the two possibilities of what it is:

(1) the world-suggestor is God (a basically Berkleyan view);

(2) the world-suggestor is reality created by God such that its existence and properties are independent of our (and other animal's) minds and it affects our senses in such a way that we have the experiences we have.

Foster takes both possibilities to be tenable and leaves it open which one is actual, or more reasonable to believe.

However, the possibility (1) is very vulnerable to the «objection from evil». Although Foster takes it to conform to Christian theism, it is hardly so: if Foster'sBerkeley's view is true then all the horrible crimes and sufferings in the world are inflicted directly by God's world-suggesting activity; in particular, (as Karl Popper remarks on Berkeley's idealism) «Christ's physical suffering is no longer inflicted upon Him by men but by immediate action of the deity» [Popper, 1983: p. 84].

So let us consider the second possibility. There is something Foster calls «the sensory organization», which is

- created by God with purpose of constituting the world for us;

- nonmental;

- causally responsible for our experiences and their orderliness, for the world appearing experientially (empirically) as it does.

The sensory organization (or the control system, or the world-suggestor, if it is not God himself) is, with respect to human minds, external mind-independent reality responsible for all our experiences, just like the physical world for the physical realist. Consider now the question: what we can know, or hypothesize, about this reality. It seems that if we can know, or hypothesize, about it anything at all (besides that it is something God-created that produces our experiences), it is exactly the same that, on the view of the physical realist, we can know, or hypothesize, about the physical world. If so, we can wonder: why this external reality is not to qualify as the physical world, in the sense of physical realism? Does the difference between this version of phenomenalistic idealism and physical realism boil down

ical science approximately uncovers». We reasonably hope and expect that science approximately uncovers this nomological structure; however, we have no guarantees that it does. Physical realism perfectly agrees with the logical (epistemic, or metaphysical) possibility that science fails in this endeavour. 
to verbalism, to Foster's insistence on putting the word «physical» on the side of the empirical world-how-it-appears-to-us rather than on the side of external reality?

Foster himself admits that «[i]n the framework of physical realism, we would think of the sensory organization as stemming from the presence of the physical world, realistically construed, and the ways in which, under the control of certain psychophysical laws, it is disposed to affect human sensory experience: it would be the physical world itself that controlled the course of experience and imprinted, as it were, its own character on it» [Foster, 2008: p. 112]. Moreover, Foster claims that «adopting a phenomenalistic idealist account of the physical world does not prevent him from accepting the existence of an external - mind-independent - reality of the same structural and organizational kind as the world of the realist, and taking this reality to be what controls the course of sensory experience» [ibid.: p. 116].

After making the latter statement, Foster remarks that «[i]t might seem that an idealist who adopted this position would be a physical realist in all but name - that he would be endorsing the realist view of the ultimate nature of reality, both within the realm of human mentality and outside it, but refusing to allow the external component of this reality its conventional title». Against this objection, Foster answers that «[t]he idealist's refusal to recognize the external reality as the physical world... is a consequence of his insistence that it is a quite different reality that all our physical beliefs are about», «that what determines the truth-values of these beliefs is not how things stand in the external reality, but how they stand in a reality that is constituted by the relevant facts about human sensory experience, or by some richer complex in which such facts centrally feature» [ibid.].

However, this explanation does not make phenomenalistic idealism differ from physical realism in any ontological respect (the view of reality); the difference indicated is merely epistemological. It concerns only the issue of what our physical beliefs are about. Foster holds the view that our physical beliefs, and the science of physics are not about external reality itself but about the empirical world-how-itappears-to-us. That is basically Kantian view that reality as «thing-in-itself» is entirely unknowable and positively inconceivable (in the sense of our being incapable to form a positive conception of it, to be distinguished from negative conceivability, which is a matter of coherence), and all our knowledge is about "phenomena», which are a matter of appearances.

This epistemological point is the only one in which Foster's phenomenalistic idealism differs from ordinary physical realism. Ontologically, such «phenomenalistic idealism» is not idealism at all but Cartesian dualism: it holds that all there is fundamentally (except God) are realities of two kinds: minds and external nonmental reality - the external reality that other Cartesian dualists, as well as materialists, call «the physical world»; and it holds that human minds are closely connected and causally interacting with specific parts of the external reality - those parts that other Cartesian dualists, as well as materialists, call «human bodies» or «brains».

However, it seems that there is another important point in which Foster's view falls foul not with physical realism generally but with what science tells us about the world. 
This point is about the pre-human history of the world. Foster's view seems to be that the physical world is a world for us not merely in the Kantian sense but also in the sense that all that constitutes this world, the external reality included, was created by God with the exclusive purpose of constituting a world for us. In that case, it seems that the external reality should differ from what scientists tell us, insofar as its pre-human history is concerned. One can, of course, suppose that God could have created something that first Big-Banged and then evolved into «the sensory organization» constituting (in conjunction with properties of our minds) the world for us. However, such an answer seems unnatural: why God would bother about such evolution rather than creating «the sensory organization» ready-made?

Foster's discussion of this topic [ibid.: p. 184-185] seems to evidence that he holds this «ready-made» view. However, this is not entirely sure, because in the discussion, the formulation of this view is preceded by «now suppose that» clause. This leaves open the possibility that Foster merely discusses what a phenomenalistic idealist should have said if that were the case. However, this discussion is interesting even in this conditional construal, because it reveals absurd consequences of phenomenalistic idealism.

Suppose that God has created the external reality responsible for all human experiences the very moment $(\mathrm{t})$ when $\mathrm{He}$ created the first human beings. He created this external reality so that the physical world contains all the empirical evidences that it existed and evolved long before there were first human beings. What should a phenomenalistic idealist say about this? Foster's response is:

«With respect to what is created, it is correct for him to say that the universe comes into existence at $\mathrm{t}^{\prime}$, and with respect to its mode of creation, it is correct for him to say that it comes into existence at t»,

where $t^{\prime}$ is millions of years before $t$ [ibid.: p. 185].

However, this response is just obfuscating what in itself is entirely clear about the situation described. ${ }^{9}$ In this situation, in fact, the physical world, and all that constitutes it (the external reality and human minds) was created the very moment when human beings were created, with all the (fake) vestiges of the evolution that in fact never took place. In fact, there was no anything like the Big Bang, the evolution of matter, the gradual formation of stars and planets, the emergence of life on the Earth and its prehuman evolution. In fact, dinosaurs never existed. God just has created the sensory organization in such a way that the best available empirical evidence supports the scientific hypotheses that there were those developments. However, all that is sham. ${ }^{10}$

\footnotetext{
${ }^{9} \mathrm{Cf} .:$ «I find it impossible to understand how a universe billions of years old can be what is idealistically created billions of years later» [Madell, 2009: p. 310].

${ }^{10}$ In his review, Geoffrey Madell made an important point by comparing Foster's-Berkley's view with that of Descartes. Descartes «argued that the certainty of the existence of a benevolent deity gives us certainty of the existence of a mind-independent world». It cannot be the case that «a benevolent God has arranged things in such a way that we all have a view of rea-
} 
Note that unlike in the case of the spatial swap scenario, in this case, it is perfectly clear what we would (not) say about how things were «physically». If we knew that in fact, no external reality existed before human beings, we would not say that the physical world (the Bing Bang, dinosaurs and all such things) existed long before human beings; we would say that they did not, and that dinosaurs never existed. In this example, it is clear that our notion of physical reality sides with external reality rather than with what is suggested by the best empirical evidence (if that evidence is misleading about the state of affairs in external reality). Thus, we have the refutation of transcendental idealism rather than of physical realism.

\section{REFERENCES}

Bird, A. (2016). Overpowering: How the Powers Ontology Has Overreached Itself. Mind, 125, 341-383.

Chakravartty, A. (2003). The Dispositional Essentialist View of Properties and Laws. International Journal of Philosophical Studies, 11 (4), 393-413.

Foster, J. (1982). The Case for Idealism. London: Routledge \& Kegan Paul.

Foster, J. (2008). A World for Us: The Case for Phenomenalistic Idealism. Oxford, New York: Oxford University Press.

Garrett, B. (2010). Review. John Foster. A World For Us: The Case for Phenomenalistic Idealism. Philosophy in Review, 30 (6), 397-399.

Harre, R., Madden, E. (1975). Causal Powers. Oxford: Blackwell.

Langton, R. (1998). Kantian Humility. Oxford, New York: Oxford University Press.

Langton, R. (2004). Elusive Knowledge of Things in Themselves. Australasian Journal of Philosophy, 82, 129-136.

Lewis, D. (2009). Ramseyan Humility. In: D. Braddon-Mitchell, R. Nola (Eds.), Conceptual Analysis and Philosophical Naturalism (pp. 203-222). MIT Press.

Madell, G. (2009). Review. A World for Us: The Case for Phenomenalistic Idealism. By J. Foster. Philosophy, 84 (2), 307-310.

Popper, K. (1983). Realism and the Aim of Science. London, New York: Routledge.

Robinson, H. (1982). Matter and Sense. Cambridge, London, New York: Cambridge University Press.

Robinson, H. (1985). The General Form of the Argument for Berkleyan Idealism. In: J. Foster, H., Robinson (Eds.), Essays on Berkeley: A Tercentennial Celebration (pp. 163-186). New York, Oxford: Oxford University Press.

Shoemaker, S. (1980). Causality and Properties. In: P. van Inwagen (Ed.), Time and Cause: Essays Presented to Richard Taylor (pp. 109-135). Dordrecht: Reidel.

Whittle, A. (2008). A Functionalist Theory of Properties. Philosophy and Phenomenological Research, 77, 59-82.

Received 04.05.2019

lity which is in fact a delusion» [Madell, 2009: p. 307]. «God is not a deceiver» (Descartes). A phenomenalistic idealist would better not aggravate his situation in this respect by acceptance of the «ready-made» view about the creation, which clearly entails that God is a deceiver. 